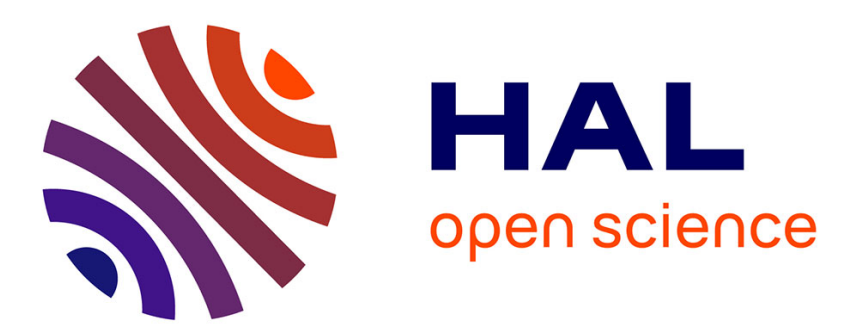

\title{
Guidelines and recommendations for indoor use of fuel cells and hydrogen systems
}

Fuster Beatrice, Deborah Houssin-Agbomson, Gilles Bernard-Michel, Guy

Dang-Nhu, Simon Jallais, Elena Vyazmina, Mike Kuznetsov, Vladimir

Molkov, Boris Chernyavskiy, Volodymyr Shentsov, et al.

\section{To cite this version:}

Fuster Beatrice, Deborah Houssin-Agbomson, Gilles Bernard-Michel, Guy Dang-Nhu, Simon Jallais, et al.. Guidelines and recommendations for indoor use of fuel cells and hydrogen systems. International Journal of Hydrogen Energy, 2017, 42 (11), pp.7600-7607. 10.1016/j.ijhydene.2016.05.266 . cea02389562

\section{HAL Id: cea-02389562 https://hal-cea.archives-ouvertes.fr/cea-02389562}

Submitted on 19 Feb 2020

HAL is a multi-disciplinary open access archive for the deposit and dissemination of scientific research documents, whether they are published or not. The documents may come from teaching and research institutions in France or abroad, or from public or private research centers.
L'archive ouverte pluridisciplinaire HAL, est destinée au dépôt et à la diffusion de documents scientifiques de niveau recherche, publiés ou non, émanant des établissements d'enseignement et de recherche français ou étrangers, des laboratoires publics ou privés. 


\title{
GUIDELINES AND RECOMMENDATIONS FOR INDOOR USE OF FUEL CELLS AND HYDROGEN SYSTEMS
}

\author{
Béatrice L'Hostis ${ }^{1}$, Deborah Houssin-Agbomson ${ }^{1}$, Gilles Bernard-Michel ${ }^{2}$, Guy Dang-Nhu ${ }^{1}$, Simon \\ Jallais $^{1}$, Elena Vyazmina ${ }^{1}$, Mike Kuznetsov ${ }^{3}$, Vladimir Molkov ${ }^{4}$, Boris Chernyavskiy ${ }^{4}$, Volodymyr \\ Shentsov ${ }^{4}$, DmitryMakarov ${ }^{4}$, Randy Dey ${ }^{5}$, Philip Hooker ${ }^{6}$, Daniele Baraldi ${ }^{7}$, Evelyn Weidner ${ }^{7}$, Daniele \\ Melideo $^{7}$, Valerio Palmisano ${ }^{7}$, Alexandros Venetsanos ${ }^{8}$, Jan Der Kinderen? \\ ${ }^{1}$ Air Liquide R\&D, Paris-Saclay Research Center, BP 126, 78354 Jouy en Josas (France) \\ ${ }^{2}$ CEA, Centre de Saclay, 91191 Gif sur Yvette (France) \\ ${ }^{3}$ KIT, Herman-von-Helmholtz Platz 1, 76344 Eggenstein-Leopoldshafen (Germany) \\ ${ }^{4}$ University of Ulster, HySAFER Centre, Newtownabbey, BT37 0QB (United Kingdom) \\ ${ }^{5}$ CCS, 11 Church Road, Great Bookham, Surrey KT23 3PB (United Kingdom) \\ ${ }^{6}$ HSL, Harpur Hill, SK17 9JN Buxton (United Kingdom) \\ ${ }^{7}$ JRC, Westerduingweg 3, POB2, 1755 ZG Petten (The Netherlands) \\ ${ }^{8}$ NCSRD, Patriarchou Gregoriou Str. 15310 Aghia Paraskevi (Greece) \\ ${ }^{9}$ HFCS, Westervoortsedijk 73, 6802 EG Arnhem (The Netherlands)
}

\begin{abstract}
Hydrogen energy applications often require that systems are used indoors (e.g., industrial trucks for materials handling in a warehouse facility, fuel cells located in a room, or hydrogen stored and distributed from a gas cabinet). It may also be necessary or desirable to locate some hydrogen system components/equipment inside indoor or outdoor enclosures for security or safety reasons, to isolate them from the end-user and the public, or from weather conditions.
\end{abstract}

Using of hydrogen in confined environments requires detailed assessments of hazards and associated risks, including potential risk prevention and mitigation features. The release of hydrogen can potentially lead to the accumulation of hydrogen and the formation of a flammable hydrogen-air mixture, or can result in jetfires. Within Hyindoor European Project, carried out for the EU Fuel Cells and Hydrogen Joint Undertaking safety design guidelines and engineering tools have been developed to prevent and mitigate hazardous consequences of hydrogen release in confined environments. Three main areas are considered; Hydrogen release conditions and accumulation, vented deflagrations, jet fires and including under-ventilated flame regimes (e.g., extinguishment or oscillating flames and steady burns). Potential RCS recommendations are also identified.

\subsection{INTRODUCTION}

Within Hyindoor European project carried by Fuel Cell Joint Undertaking, a consortium of FC and Gas companies, Testing laboratories, Research Institute and Leading actors in RCS development $i$ in charge of prenormative research about $\mathrm{H} 2$ indoor energy applications. These systems often require to be used indoors (e.g., forklifts in warehouse, refuelling stations, fuel cells for offgrid or backup applications; see Fig. 1). 

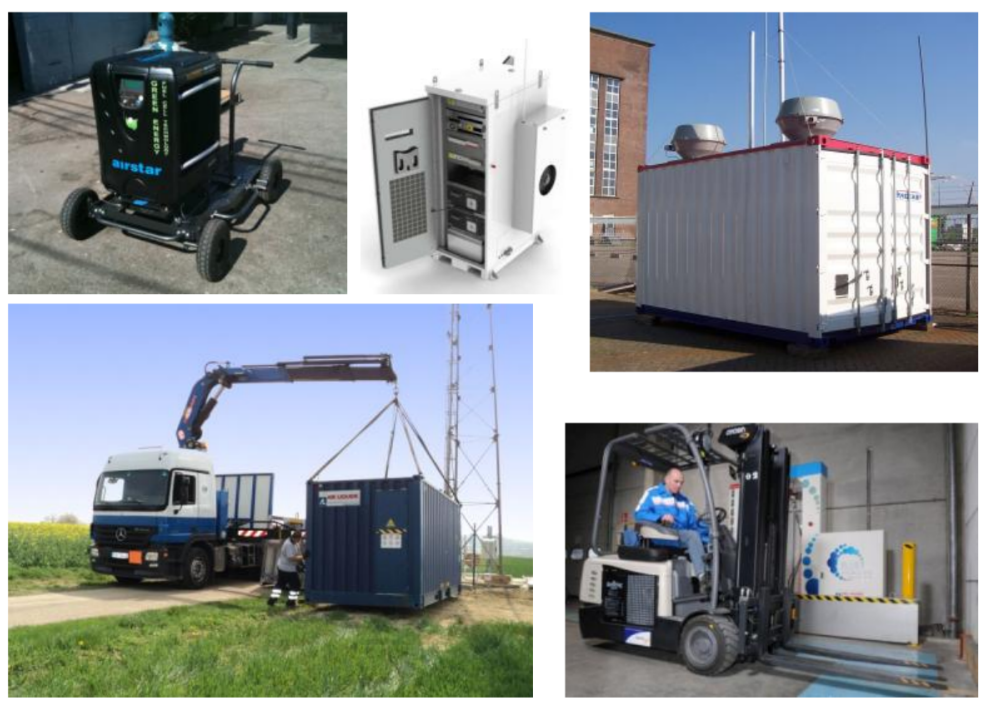

Figure 1. Examples of hydrogen energy applications. (Photo credit: HyGEAR, Air Liquide)

It may also be necessary or desirable to locate some hydrogen system components/equipment in indoor or outdoor enclosures for security or safety reasons to isolate them from the end-user and the public, or from weather conditions. Use of hydrogen in confined environment requires detailed assessment of hazards and associated risks, including potential risk prevention and mitigation features.

Closing knowledge gaps is critical to this effort ,four main topics were addressed in Hyindoor project:

- Hydrogen release inside a confined or semi-confined enclosure;

- Indoor hydrogen-air deflagration;

- Jet fire and underventilated fire;

- Hydrogen detection for confined spaces.

These topics were studied through:

- A review of the state of the art on published information and critically analyzed in order to prioritize the research objectives;

- Targeted experiments specifically performed in Hyindoor project;

- Evaluation and validation of analytical and numerical approaches to assess phenomena.

The generated knowledge has been translated into state-of-the-art safety guidelines including specific engineering tools supporting their implementation.

Recommendations have been formulated with regards to evolutions needed in the Regulations Codes and Standards framework at European and International levels to support the safe introduction of fuel cells and hydrogen in early markets.

The outputs of the project is being and will be disseminated to the hydrogen safety community through different channels including international and national associations (IA-HySafe, EHA, EIGA, etc.), standard development organisation (ISO, CEN, etc.), national regulators (e.g. HSE/HSL in the UK) and educational/training programs (e.g. MSc course in Hydrogen Safety Engineering and International short course and advanced research workshop series "Progress in Hydrogen Safety" at Ulster). 
There are three generic safety objectives for any safety system including for use of hydrogen systems indoors:

- Life safety;

- Property protection;

- Environment protection.

Primary consideration should be given to life safety, including site workers, customers and general public. The life safety objectives may include, but not limited to (Saffers and Molkov, 2014):

a) The occupants are able to leave building/facility in reasonable time, or consequences to occupants are acceptably low;

b) First responders are able to operate in reasonable safety;

c) Collapse or debris does not endanger bystanders, first responders and other people likely to be near facility.

A number of general safety rules, strategies and recommendations for hydrogen infrastructure design and utilization had been identified within HyIndoor project. These include (as described in the public Guideline on fuel cell indoor installation and use):

- Consider whether it is really necessary to house the hydrogen system within a room / enclosure, or whether it could be relocated outdoor where accidental leak would less likely lead to accumulation of hydrogen in flammable concentrations due to better ventilation;

- Reduction of hydrogen supply pipeline diameter and operational pressure to the minimum required to satisfy technological requirements for mass flow rate If decrease of pipe diameter is impossible or undesirable, utilization of flow restrictors;

- Minimization of hydrogen operational pressure whenever possible;

- Sighting of hydrogen infrastructure in a way ensuring jet decay before impingement on neighbouring obstacles in order to prevent formation of the layers with flammable hydrogen concentration;

- Identification, and, where possible, reduction of number and separation of potential ignition sources;

- Utilization of storage tanks with high fire resistance rating to ensure at least sufficient time for evacuation of people;

- Minimization of hydrogen inventory to prevent formation of flammable mixture in confined enclosure even after complete release and dispersion of hydrogen or limit it below amount which will produce structural damage in low strength equipment and buildings in case of deflagration

- Evaluation of deterministic separation distances before quantitative risk assessment (QRA). Deterministic separation distances can be calculated for unignited releases and for well-ventilated jet fires using published and validated nomograms (Molkov, 2012)

- Consider preferential use of side vents over roof vents in order to improve passive ventilation and vertical versus horizontal vents of the same area

- Consider preferential use of several vents over a single vent of the same area with difference in height of vents location as large as possible and vents located on all sides of the building to enhance wind-assisted venting irrespective of its direction;

- Consider exclusion of venting pipes and ducts as much as possible;

\subsection{GUIDELINES AND MITIGATION STRATEGIES}

\subsection{Risk events and Safety strategies with hydrogen use}

Research results and methodologies developed within HyIndoor project have been used to compile the Guideline for fuel cell indoor installation and use (available on the Hyindoor web site). This section begins with the introduction of the objectives of hydrogen safety and provides reference definitions of the terms and concepts used in the field of hydrogen safety. It goes on to list the general rules and best practices of hydrogen safety, compiled on the basis of industry experience and insights obtained within HyIndoor project research. Guidelines document also includes an overview of harm criteria relevant to the hydrogen safety. 
Analysis of the phenomena relevant to the hydrogen safety and their interrelations lead to development and inclusion in Guidelines the phenomena and consequences diagram (see Fig. 2). The diagram graphically represents potential chains of events associated with indoor incidents/accidents involving hydrogen systems and infrastructure and its consequences. More detailed description of individual elements of the diagram is provided in the public document.

Guidelines also outline the principles of Hydrogen Safety Engineering (H2SE) and approaches it uses.

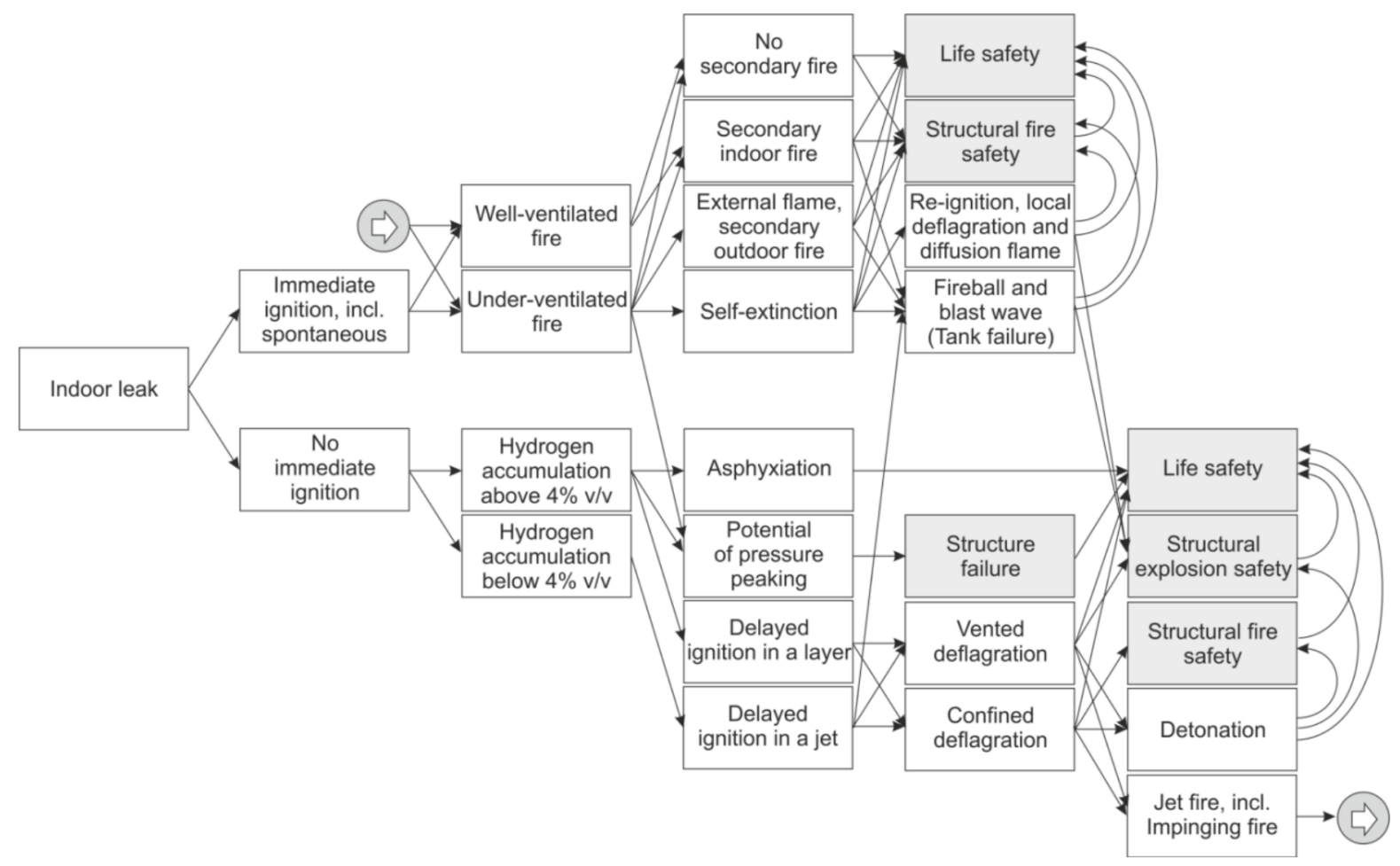

Figure 2. Phenomena and consequences diagram. White boxes - various phenomena, starting with the development of hydrogen leak. Grey boxes - potential consequences. Note that even if no immediate ignition has occurred (lower branch), subsequent chain of events can lead to delayed ignition leading to transition to the upper branch, as indicated by arrow in a circle pictograms.

The main body of the guidelines includes description of three main types of phenomena studied within HyIndoor project - hydrogen release and dispersion, deflagration and jet fires, lists hazards associated with each type and recommendations for mitigation of consequences and provides the practical outcome of research conducted within the project.

The main body of the Hyindoor guidelines public report is followed by appendices which include more technical descriptions of methods and techniques developed within HyIndoor project. They include equations and engineering nomograms obtained during the project research and their derivations, instruction for their application and examples of their utilization for representative engineering problems. Methodologies and nomograms listed in appendicies include:

- Nomogram for concentration decay in momentum-dominated jet;

- Nomogram to determine a leak rate leading to $100 \%$ of hydrogen in the enclosure;

- Nomograms for determination of overpressure due to pressure peaking phenomena;

- Nomograms for determination of 'safe' tubing diameter and blowdown duration with account for pressure peaking phenomenon;

- Equations and nomogram for steady state concentration in enclosure with one vent;

- Derivation of Thermodynamic model used for formulation of inventory limitation rule; 
- Vent sizing correlation for low strength equipment and enclosures (entirely filled in with flammable mixture);

- Vent sizing correlation for the localized mixture deflagration;

- Dimensionless flame correlation;

- The equation for the effect of restrictor on the jet flame length;

- Methodology for calculation of the thermal radiation from a hot layer and ceiling during wellventilated fire.

\subsection{Recommendations from Hyindoor research results}

Analysis of the research results of Hyindoor project were enabled to define guidelines and best practices easily usable by engineers for indoor safety use of hydrogen energy applications.

\subsubsection{About releases in confined space and consequences assessment}

Recommendations were defined and can be applied at the conception level of a hydrogen energy application, allowing the safety to be increased.

These recommendations mainly concern the optimization for the increase of the effectiveness of the natural/passive ventilation.

These recommendations are the following:

- In order to prevent accumulation of flammable concentrations of hydrogen an enclosure should be provided with adequate passive vent(s). If practical, ventilation system should be designed to prevent concentrations exceeding LFL for realistic expected hydrogen release rates.

- Utilization of two (or more) vents located at different height is preferable; this ventilation configuration is more effective than a single vent (or more) only located at the top of the enclosure, considering the same total ventilation area.

- A one-opening ventilation configuration can be used when a two-openings ventilation configuration is not possible;

- Vents on vertical side walls of the enclosure are preferable to horizontal roof vents.

- Obstructions - like grids or ducts in front of the ventilation vents should be avoided. When it is not possible (e.g., due to thermal or security reasons), account should be taken for the reduction of the ventilation performance. The effective ventilation area has to be re-calculated and a correction factor addressing efficiency reduction should be introduced in order to take into account the reduction of the discharge coefficient due to vent obstruction.

- Forced venting could be applied in cases when purely passive ventilation is impractical, e.g. since it requires too large vents unacceptable at cold climate. It should be recognised, however, that such systems are not necessarily fail-safe and the reliability of the forced ventilation system needs to be considered;

- PPP has to be taken into account in risk assessment.

Calculation means for the design, for consequences and mitigation assessment were studied in Hyindoor to propose some tools (e.g. nomograms, simple analytical models...). 
Thus proposed calculation means for build-up assessment and ventilation system sizing are the following:

- Ventilation system parameters can be calculated using engineering tools described in Hyindoor Guidelines report (Deliverable 5.1):

○ For one-opening ventilation mode

- The passive ventilation approach proposed by Molkov et al. (2014)

- By using equations

- By using proposed nomograms

- The natural ventilation approach proposed by Linden (1999); the simple expression developed by Cariteau and Tkatschenko (2013) is validated and usable (see Hyindoor Guidelines report (Deliverable 5.1))

- For two-openings ventilation mode

- The natural ventilation approach proposed by Linden (1999) (see Hyindoor Guidelines report (Deliverable 5.1))

- Waiting new developments, forced ventilation in an enclosure with one opening could be calculated using equations of Hyindoor Guidelines report (Deliverable 5.1).

- Computational Fluid Dynamics (CFD) can be a promising approach especially for complex geometries, multiple vents and release parameters different from those more classical considered to develop analytical engineering tools.

- PPP can be assessed using Brennan and Molkov (2013) theoretical model, or using the experimental correlation proposed in Hyindoor Guidelines report (Deliverable 5.1).

\subsubsection{Consequences assessment and mitigation of hydrogen-air deflagration}

Experimental, analytical and numerical works on hydrogen-air deflagration were carried out in Hyindoor project. The critical analysis of these results allowed recommendations to be defined. These recommendations to limit deflagration consequences are the following:

- Venting of deflagrations is the most widespread technique to mitigate explosions in an enclosure decreasing overpressure.

- Apertures initially dedicated to ventilation will participate in the venting of the explosion.

- The size of the vents should be chosen to ensure that overpressure produced by mixture deflagration will not exceed structural strength of the enclosure.

- Internal overpressure in case of ignition decreases with increase of vent surface(s).

- Position potential ignition sources close to explosion relief vent if possible.

- When possible prefer vents dedicated to natural/passive ventilation without obstruction (or minimizing obstruction: grids for instance) to limit overpressure in case of deflagration.

- Avoid or minimize internal congestion in the enclosure.

- The gases vented from a deflagration need to be discharged into a safe area.

Associated calculation means proposed are given below:

- State-of-the art correlation for vent sizing developed within the HyIndoor project is presented in Hyindoor Guidelines report.

- Vent size can be calculated using analytically derived and experimentally validated correlations between allowable overpressure, enclosure volume, flammable mixture parameters, and vent area. Hyindoor Guidelines report presents a correlation for the case of hydrogen fraction uniform across the entire enclosure (Chernyavsky et al., 2014). Guidelines report presents a technique to calculate 
vent size for the case when hydrogen-air mixture occupies only part of the enclosure volume, i.e. a layer with uniform and non-uniform concentration.

- CFD may be used to predict vented deflagration pressure dynamics, particularly - where simplified engineering models are not applicable.

- However, care should be taken to ensure that CFD models are validated within range of parameters for which they are applied, including:

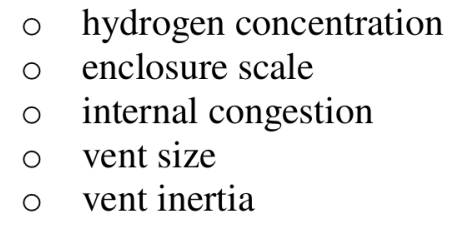

\subsubsection{Dealing with jet fire and underventilated fire}

Work performed on jet fire and underventilated fire in Hyindoor project gave the following recommendations to take into account for application design:

- Where practicable, avoid the conditions for under-ventilated jet-fires to occur by providing sufficient ventilation. This may be achieved by providing sufficient passive vents to maintain an average concentration of less than the LFL resulting from an unignited hydrogen leak.

- Use fire resistant materials where possible;

- Avoid the presence of combustible materials close to vents if there is a potential for an underventilated jet-fire to occur.

- Consider protection against under-pressure due to rapid steam condensation (e.g. by providing vents for emergency air inflow or inert gas injection).

In the project, calculation means were studied and can be proposed:

- Hyindoor Guidelines report presents the dimensionless correlation for calculation of flame length (Molkov and Saffers, 2013). Results of the flame length calculation can be used to find out three deterministic separation distances for well-ventilated jet fires. An example of the tool for calculation of deterministic separation distance is provided in Appendix part of the Hyindoor Guidelines report;

- Use piping of smallest possible diameter or introduce flow restrictors to reduce flame length (flame length is generally proportional to leak diameter). An example of calculation of the effect of flow restrictor on flame length is provided in Appendix part of the Hyindoor Guidelines report;

- Radiation heat flux from the hot layer of combustion products and heated ceiling can affect the evacuation. The methodology to calculate thermal radiation and example based on HSL experiment are given in Appendix part of the Hyindoor Guidelines report;

- Computational fluid dynamics (CFD) can be used as a contemporary tool for hydrogen safety engineering in assessment of jet fires indoors as no other tool available.

\subsection{RCS ISSUES: from state of the art to recommendations}

Unignited hydrogen release indoors can result in accumulation of hydrogen in the facility. Hazards include:

a) Formation of flammable mixture that potentially could combust if ignited with hazardous pressure and thermal effects;

b) Destruction of enclosure or building by the pressure peaking phenomena during unignited release;

c) Asphyxiation that can result from displacement of breathable air by the hydrogen.

Only the two first events are addressed by Hyindoor project and will be treated in this chapter. 
For each phenomenon: Hydrogen release conditions and accumulation, Vented deflagration, Jet fire and under-ventilated flame regimes (e.g., extinguishment or oscillating flames and steady burns) the release position/conditions, the number, size and location of the openings in the room/enclosure of some given size, and the type of ventilation can significantly influence the prevention/mitigation strategy.

Each of these phenomena has been subject to analytical, experimental and numerical analysis within a dedicated work package. They each have shared state of the art information in order to prioritize the research objectives. Existing analytical and numerical models were initially used as well as RCS lists (which were updated from time to time) were prepared and RCS gaps were identified. These results were used to facilitate the formulation of the test program, while the experimental results were subsequently used to validate and improve the models and identify RCS recommendations, where appropriate.

In most of the standards, not to say all, related to hydrogen, some basic generic requirements are usually mentioned to limit the likelihood of a release, available for indoor or outdoor uses. Examples are:

- Use inherently safe design and technologies;

- Minimize the number of connections;

- limit exposure to hazards through reliability of equipment;

- Apply safety principles when designing control systems...

These means are usually considered as intrinsically safe measures.

With regards to indoor use of hydrogen, some additional general basic requirements are often mentioned to prevent hazards associated with flammable atmosphere accumulations within the enclosure: mainly natural or mechanical ventilation. In some cases additional passive means including pipe orifices or similar methods of flow restriction are mentioned, in order to reduce the accumulation of hydrogen above the lower flammability limit (LFL).

In most cases, a specific risk assessment is required for all stages in the life cycle and all types of potential hazards. The results of the hazard and risk assessment process shall be used both to evaluate the consequences of hazardous events and to determine appropriate risk reduction.

Sometimes specific additional measures and tests are required for specific risk like shock and vibration, for example for mobile applications but not only. It is rarely mentioned that an exhaustive list of hazards or, even better, a standard fault-tree analysis or bow-tie diagram dedicated to outdoor or indoor use of hydrogen needs to be considered.

Part of the requirements remains qualitative without referencing engineering tools, models or methodology. Sometimes, references are made to more specific detailed standards.

With regards to confined spaces, ventilation is generally mentioned as a main requirement in order not to reach a concentration above 25 or $50 \%$ of the lower flammability limit (LFL). Reference is made to normal, nominal, foreseeable, abnormal or accidental or other kinds of releases without anymore precision or detailed definition. It also should be noted that, in some standards, hydrogen purges are clearly mentioned as having to be taken into account (for example for fuel cell systems).

In most of the standards, reference is made to standard IEC 60079-10-1 for determining the extent of the flammable region at the source of the release and within the confined area. This standard is a harmonized standard with European so-called ATEX Directive for the prevention of the formation of explosive atmospheres. This IEC standard is not dedicated to hydrogen. It is intended to be applied where there may be a risk of ignition due to the presence of flammable gas or vapor of all kinds (for example methane, gasoline vapors, acetone, hydrogen...) mixed with air under normal atmospheric conditions. As being applicable to different kinds of gases, the generic method described in the standard does not take into account the specific characteristics of a hydrogen release (density, buoyancy, stratification...) and generally overestimates the 
concentration in the confined space. There are usually no engineering models, or other methods, mentioned in standards for assessing the hydrogen concentration within an enclosure.

In this IEC standard, it is clearly stated that the catastrophic failures which are beyond the concept of abnormality dealt with in this standard does not have to be considered for the so-called ATEX zoning (for example to the rupture of a process vessel or pipeline or events that are not predictable). But the likelihood of such catastrophic events is limited by appropriate design defined in the existing pressure equipment and piping regulation, standards, codes and practices.

Within existing standards, it is also admitted that the boundary for dilution of normal internal releases to below $25 \%$ (LFL) may be verified by computational fluid dynamic analysis, tracer gas, or similar methods, such as those given in IEC 60079-10.

For natural ventilation, openings and ducts are usually mentioned without any detailed information for determining the sizing of these openings. It is also usually mentioned that these openings shall not become obstructed or compromised when the system is normally operated. In some cases, requirement for openings in an enclosure can be contradictory with other requirements on protection from access to hazardous parts complying with a minimum IPXXB or IP2X minimum rating as outlined in Degrees of Protection Provided by Enclosures (IP Code), IEC 60529, including ingress of water.

Gas detection within the confined space is mentioned as possible mitigation measure within most of the standards. If gas detection is employed as a critical safety component, the gas detection system shall usually comply with IEC 60079-29-1 and ISO 26142. The IEC Standard 60079-29-1 specifies general requirements for construction, testing and performance, and describes the test methods that apply to portable, transportable and fixed apparatus for the detection and measurement of flammable gas or vapor concentrations with air.

Usually the detection is intended to trigger the appropriate action determined by the risk assessment of the system, including the prompt shutdown of the equipment or the stating up and monitoring of the ventilation equipment (like fan, blowers...). Failure of ventilation shall cause the system to respond in such a way that shall mitigate any hazard or prevent the creation of additional hazards in accordance with the Safety/Hazard Analysis. This may include shutting off; either through the detection of high gas/vapor concentration or with ventilation interlocks provisions.

In summary, results from Hyindoor will bring valuable inputs for improving guidelines \& RCS recommendations and filling some existing gaps in current guidelines and standards as:

- Recommending to use in a proper way flow restrictions in order to limit the maximum flow rate in case of hydrogen leaks;

- Giving General qualitative/quantitative requirements for designing the openings for natural ventilation;

- Proposing validated engineering tools and models for assessing hazard related to hydrogen accumulation within an enclosure, with some different standards configuration of openings;

- Proposing practical nomograms based on these engineering tools and models;

- Proposing a generic phenomena and consequences diagram.

The final report on RCS recommendations has collected results from all Hyindoor Work Packages, built consensus within the group and presented them in a comprehensive report. The objective was to summarize the regulations, codes and standards (RCS) findings of the Hyindoor project and to categorize them to support RCS initiatives. The categories are:

a) Ventilation : Recommendations \# 1-8

This section covers recommendations regarding the implementation of ventilation for preventing the formation of an explosive atmosphere, or for limiting the hydrogen concentration, in the event of a hydrogen leak release. 
b) Limitations of over-pressure: Recommendations \# 9-11

This section covers recommendations regarding the implementation of venting devices for limiting the overpressure developed in the event of a hydrogen release as a result either of the Pressure Peaking Phenomenon (PPP) or of the deflagration of a flammable hydrogen-air mixture.

c) Other: Recommendations \# 12-14

This section covers jet-fire, sensors and flow restrictors.

Also, the RCS report includes a path forward with the aim to bring these recommendations to the international RCS bodies (e.g. ISO, IEC) and professional associations (AFGC, EIGA, CGA).

\subsection{RCS strategy transfer and conclusions}

First of all, the public releases of the guideline, RCS report and final report will be obviously the means for dissemination of the results of Hyindoor project.

There are several perspectives of the Hyindoor project:

- Concerning RCS, since project partners (AL, UU, CCS, CEA) are also members to the ISO committees, they will push forward for that Hyindoor recommandations will be implemented in the new international norms.

- Concerning the scientific perspectives, the consortium has identified some remaining research gaps that still have to be filled. These gaps are the comprehensive design of forced ventilation systems, the structural response of structures (containers for example) to internal explosions, the prediction of the consequences for vented explosion in realistic conditions (vent panel deployment, non homogenous hydrogen distribution, initial turbulence...) and the reliable use of CFD in risk assessment. The consortium partners have already submitted and will submit some project proposals to European and national funding institutions to perform the pre-normative research on these still open research gaps.

\section{ACKNOWLEDGEMENTS}

The authors wish to acknowledge the European Union Fuel Cells and Hydrogen Joint Undertaking for funding and supporting the Hyindoor project, and also acknowledge the support and input of partners in the Hyindoor project.

\section{REFERENCES}

Bauwens, C.R., J. Chaffee, S.B. Dorofeev (2011) Vented explosion overpressures from combustion of hydrogen and hydrocarbon mixtures, International Journal of Hydrogen Energy, 36: 2329-2336.

Bernard-Michel et al. "CFD Benchmark based on experiments of helium dispersion in $11 \mathrm{~m} 3$ enclosure inter comparison for plumes and buoyant jets", ICHS'5.

Brennan, S. \& Molkov, V. (2013) Safety Assessment of Unignited Hydrogen Discharge from Onboard Storage in Garages with Low Levels of Natural Ventilation, International Journal of Hydrogen Energy 38 (19): 8159-8166.

Cariteau "Résultats expérimentaux sur les régimes de dispersion d'un jet d'héluim dans une enceinte". B. Cariteau. CEA report RT/2010-016/A, 2010.

Giannissi S.G., Shentsov V., Melideo D., Cariteau, B, Baraldi D., Venetsanos A.G., Molkov V. "CFD benchmark on hydrogen release and dispersion in confined, naturally ventilated space with one vent". Int. J. of Hydrogen Energy, 40: 2415-2429.

Hooker. "Accumulation of hydrogen released into a vented enclosure - experimental results", Hooker P., Willoughby D., Hall J. and Hoyes J., ICHS'5. 
Keenan J, Makarov D. and Molkov V. (2013a) Towards the Implementation of Rayleigh-Taylor Instability into the Multi-Phenomena Deflagration Model. In: Seventh International Seminar on Fire \& Explosion Hazards (ISFEH7), Providence, RI, USA. Research Publishing. 932-941.

Keenan J, Makarov D. and Molkov V. (2013b) Modelling and effect of Rayleigh-Taylor instability on coherent deflagrations, Proc. of Int. Conference on Hydrogen Safety, 9-11 September 2013, Brussels, Belgium.

Keenan J, Makarov D. and Molkov V. (2014) Rayleigh-Taylor instability: Modelling and effect on coherent deflagrations, Int. J. Hydrogen Energy, V.39 (35), pp. 20467-20473.

Kumar R.K. (2006) Vented combustion of hydrogen-air mixtures in a large rectangular volume. Collection of technical papers - 44th AIAA Aerospace Sciences Meeting, V.6, 2006, pp. 4398-4406.

Makarov D., Molkov V. (2013a) Numerical Simulation of 10\% Hydrogen-Air Vented Deflagration in a 120 m3 Enclosure, Seventh International Seminar on Fire \& Explosion Hazards (ISFEH7), Providence, RI, USA. Research Publishing.

Makarov D., Molkov V. (2013b) Modelling and simulation of lean hydrogen-air deflagrations in $120 \mathrm{~m} 3$ enclosure, Proc. of Int. Conference on Hydrogen Safety, 9-11 September 2013, Brussels, Belgium.

Molkov V., V. Shentsov, S. Brennan, and D. Makarov (2014), Hydrogen non-premixed combustion in enclosure with one vent and sustained release: Numerical experiments, Int. J. Hydrog. Energy, vol. 39, no. 20, pp. 10788-10801, Jul. 2014.

Molkov V. and Bragin M. (2013), Hydrogen-air deflagrations: vent-sizing correlation for low-strength equipment and buildings, presented at $5^{\text {th }}$ Intl. Conf. on Hydrogen Safety, Brussels, 2013.

Molkov V.(1996), Venting of gaseous deflagrations, D.Sc. Thesis, All-Russian Research Institute for Fire Protection, Moscow, 1996.

Molkov V., Dobashi R., Suzuki M., and Hirano T. (1999), Modelling of vented hydrogen-air deflagrations and correlations for vent sizing,. J. of Loss Prevention in the Process Industries, 12, pp. 147-156.

Molkov V.V. (2012), Fundamentals of hydrogen safety engineering, www.bookboon.com.

R.P. Cleaver, R.M. Marshall, P.F.Linden. "The build-up of concentration in a single enclosed volume following a release of natural gas”. 1994, Journal of Hazardous materials - vol. 36, pp. 209-226.

Saffers J.-B. and Molkov V.V. (2014), Hydrogen safety engineering framework and elementary design safety tools, Intl. J. of Hydrogen Energy, 39 (2014), pp. 6268-6285.

Tolias, I. C., Venetsanos, A. G., Markatos, N. and Kiranoudis, C. T. (2014). CFD modeling of hydrogen deflagration in a tunnel. International Journal of Hydrogen Energy, 39(35), 20538-46.

Tolias, I. C., Venetsanos, A. G., Markatos, N. C. and Kiranoudis, C. T. (2014). CFD simulation of hydrogen deflagration in a vented room. XXVI IUPAP Conference on Computational Physics, CCP2014, Boston, 1114 August.

Tolias, I. C., Venetsanos, A.G. and Markatos, N. (2013). Evaluation of the ADREA-HF CFD Code Against a Hydrogen Deflagration in a Tunnel, 5th International Conference on Hydrogen Safety, Brussels, Belgium, 09-11 Sept.

\section{回Hyindoor}

\section{Pre-normative research on safe indoor use of fuel cells and hydrogen systems}

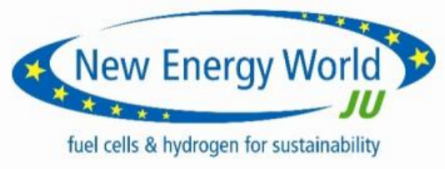

Contract Number: 278534

Project website address: $\underline{w w w . h y i n d o o r . e u}$ 